\title{
La Corte Suprema, ¿un tribunal para los empleadores? Estudio empírico del recurso de unificación de jurisprudencia laboral*
}

\author{
Luis Iván Díaz García \\ Sofía Alarcón García \\ Katerine Cempe Cempe \\ Luis Alejandro Garrido Esparza \\ Alejandro Zúniga Garrido**
}

\begin{abstract}
RESUMEN
La presente investigación evalúa la inclinación proempleador o protrabajador de los pronunciamientos laborales de la Corte Suprema de Chile. Para este efecto se analizan las sentencias emitidas en los 1.051 recursos de unificación de jurisprudencia deducidos en el cuadrienio que se inicia con su incorporación al ordenamiento jurídico nacional. Este estudio empírico permite concluir, en lo esencial, que la Corte Suprema favoreció la posición de los empleadores en el 95,2\% de los casos. En este sentido, el máximo tribunal aparece extraordinariamente desalineado respecto de las posiciones jurisprudenciales sostenidas por las Cortes de Apelaciones y los juzgados de instancia que conocieron de las mismas materias y, lo que es más grave, respecto de los requerimientos de tutela de los derechos de los trabajadores.
\end{abstract}

Derecho del trabajo - unificación de jurisprudencia - Corte Suprema

$$
\begin{aligned}
& \text { The Supreme Court, a court for employers? } \\
& \text { Empirical study of the jurisprudence unification recourse }
\end{aligned}
$$

ABSTRACT

This research assesses the pro-employer or pro-worker orientation of the Chilean Supreme Court rulings on labor law cases. For this purpose the decisions made in the 1,051 jurisprudence

* Esta investigación ha sido desarrollada en el marco de la ejecución del proyecto FONDECYT 11121310 , cuyo investigador responsable es Luis Iván Díaz García.

Agradecemos los valiosos aportes formulados por los académicos Dr. Alberto Olivares Gallardo, Dr. Darío Parra Sepúlveda, Mg. Eduardo Castillo Vigouroux y Dr. Luis Lloredo Aliste, a una versión preliminar de este texto que permitieron mejorarlo sustancialmente.

** Abogado Pontificia Universidad Católica de Chile. Doctor en Derecho Universidad Carlos III de Madrid, España. Profesor de Derecho, Facultad de Ciencias Jurídicas de la Universidad Católica de Temuco. Correo electrónico: ivandiaz@uct.cl. Sofía Alarcón García es egresada de Derecho por la Universidad Católica de Temuco. Correo electrónico: palarcon2009@alu.uct.cl. Katerine Cempe Cempe es egresada de Derecho por la Universidad Católica de Temuco. Correo electrónico: kcempre2009@alu.uct.cl. Alejandro Garrido Esparza es egresado de Derecho por la Universidad Católica de Temuco. Correo electrónico: lgarridoe2009@ alu.uct.cl. Alejandro Zúñiga Garrido es egresado de Derecho por la Universidad Católica de Temuco. Correo electrónico: azunigag2009@alu.uct.cl.

Artículo recibido el 13 de agosto de 2014 y aceptado para su publicación el 27 de marzo de 2015. 
unification recourses that have been brought to the Court in the quadrennium that began when it was incorporated to the national legal system. This empirical study allows us to conclude, essentially, that the Supreme Court favored the employers' positions in 95.2\% of the cases. In this sense, the higher court seems extraordinarily far away from the decisions made by the Courts of Appeal and in the first stage courts that knew the same issues and, which is more serious, regarding the requests for protecting workers' rights.

Labor law - Unification jurisprudence recourse - Supreme Court

\section{INTRODUCCIÓN}

$\mathrm{E}$ 129 de marzo de 2008 se publicó en el Diario Oficial la Ley 20.260 que, junto con modificar ciertos aspectos procesales de la Ley 20.087, incorporó al ordenamiento jurídico chileno el recurso de unificación de jurisprudencia. Por este medio de impugnación se pretendió corregir el controvertido sistema de recursos establecido en el proceso laboral que, en virtud de la Ley 20.087, había sido recientemente reformado ${ }^{1}$. De este modo, se otorgó a la Corte Suprema la posibilidad de establecer una jurisprudencia uniforme en el ámbito laboral, incorporándose el seguimiento del precedente en la materia ${ }^{2}$. Sin embargo, al poco tiempo la jurisprudencia emanada de la Cuarta Sala del máximo tribunal fue objeto de críticas por parte de la doctrina especializada, debido al contenido de esas decisiones ${ }^{3}$. Más allá de estas críticas de fondo,

${ }^{1}$ En este sentido y con antecedentes adicionales, ver Delgado Castro, J., "Examen crítico del recurso de unificación de jurisprudencia”, en: Revista de Derecho de la Pontificia Universidad Católica de Valparaíso ( $\mathrm{N}^{\circ} 36$, junio de 2011), p. 474.

${ }^{2}$ Aunque demostrar la efectividad de esta afirmación excede los objetivos del presente trabajo, resulta conveniente recordar que durante la tramitación parlamentaria del proyecto de ley relativo al recurso de unificación de jurisprudencia se sostuvo que el pronunciamiento de la Corte Suprema debía servir de "interpretación uniforme", de "precedente" y para "uniformar los fallos". Ver Biblioteca del Congreso Nacional (2008): Historia de la Ley 20.260, pp. 272 y 283. En la doctrina, esta acertada comprensión respecto del objetivo del recurso en análisis se puede encontrar en Romero Seguel, A., "La discriminación judicial como nuevo error decisorio litis en el proceso chileno", en Revista Chilena de Derecho (vol. 38 (2011), N²), pp. 339-348. Del mismo modo, una sistemática de los argumentos a favor de esta misma afirmación se puede encontrar en Díaz García, L. I., "Objetivo del recurso de unificación de jurisprudencia laboral", en Revista Ius et Praxis (artículo aprobado para publicación). Con todo, se debe reconocer que esta finalidad no es admitida por la doctrina chilena mayoritaria, pudiendo consultarse al efecto, por ejemplo, Díaz Méndez, M., El recurso de unificación de jurisprudencia laboral, Libromar, Santiago de Chile, 2014, p. 8; Halim, F., El recurso de unificación de jurisprudencia laboral, Puntolex y Thomson Reuters, Santiago de Chile, tomo I, 2011, p. 53; Lanata, G., El sistema de recursos en el proceso laboral chileno, AbeledoPerrot y Thomson Reuters, Santiago de Chile, segunda edición, 2011, p. 288; y Halpern, C., y Humeres, H., "La intervención de la Corte Suprema en la nueva justicia del trabajo: el recurso de unificación de jurisprudencia”, en: Actualidad Jurídica Universidad del Desarrollo, año XI, No 21, 2010, p. 353. En cualquier caso, una toma de posición acerca del problema exige tener presente el artículo 483-C, que textualmente dispone: "El fallo que se pronuncie sobre el recurso solo tendrá efecto respecto de la causa respectiva, y en ningún caso afectará a las situaciones jurídicas fijadas en las sentencias que le sirven de antecedente".

3 Al respecto puede verse, por ejemplo, Arellano Ortiz, P., y Ponce Heinsohn, I., "Interpretación jurisprudencial del beneficio de la semana corrida: violación del principio de igualdad de remuneraciones", 
se intuía (a partir de la consideración de ciertos casos particulares) un giro consistente en una notable inclinación hacia las pretensiones formuladas por los empleadores y en desmedro de las sostenidas por los trabajadores.

En ese contexto, el objetivo de la presente investigación consiste en determinar si las resoluciones de la Corte Suprema recaídas en el recurso de unificación de jurisprudencia laboral favorecen las posiciones sostenidas por los empleadores o por los trabajadores. Con tal finalidad se analizan los recursos deducidos entre el 30 de marzo de 2008 y el 29 de marzo de 2012, que es el cuadrienio que sigue a la fecha del inicio de su vigencia. De este modo se revisan sentencias pronunciadas entre el 19 de noviembre de 2008 y el 11 de abril de 2013, pues la resolución de dichos recursos tardó algún tiempo en ser emitida por el máximo tribunal.

De acuerdo con lo que se viene diciendo, la pregunta que guía esta investigación se puede formular del siguiente modo: ¿a quién favorecieron, en el período referido, las decisiones de la Corte Suprema cuando resolvió los recursos de unificación de jurisprudencia laboral? La hipótesis es que el máximo tribunal optó, mayoritariamente, por las posiciones procesales del empleador, en desmedro de los intereses de los trabajadores.

Aunque parece obvio, resulta imprescindible destacar que en las siguientes líneas no se evalúan las decisiones en particular, esto es, si lo decidido en tal o cual caso fue acertado o no. Lo que esta investigación persigue es un análisis de tendencias en las preferencias de la Corte Suprema frente a las pretensiones sostenidas por empleadores y por trabajadores. Este control de la actividad jurisdiccional se vuelve más necesario en el contexto de sistemas recursivos que pretenden la uniformidad de la jurisprudencia, como es el caso del recurso de unificación objeto del presente estudio.

Por lo demás, conviene advertir que desde marzo del 2014 se ha producido un notable giro en la tendencia jurisprudencial de la Corte Suprema, desde entonces claramente inclinada a favorecer los derechos de los trabajadores. Por ello no se debe perder de vista que, según se advirtió poco más arriba, el presente estudio analiza las sentencias recaídas en el recurso de unificación de jurisprudencia pronunciadas entre el 19 de noviembre de 2008 y el 11 de abril de 2013.

Desde el punto de vista estructural, la exposición se vertebra en torno a tres apartados. En el primero de ellos se ofrece un marco conceptual, con la finalidad de precisar el significado que se atribuye a ciertas expresiones y categorías utilizadas en el trabajo. En el segundo se expone la metodología utilizada para alcanzar el objetivo de la investigación. En el tercer apartado se presentan los resultados obtenidos, distinguiéndose ciertos aspectos preliminares de los resultados propiamente tales, pero siempre en un

en Revista de Derecho (Valdivia) (vol. XXIV, No 2, diciembre 2011, pp. 27-234; Caamaño Rojo, Eduardo, "Otra vuelta de tuerca a la jurisprudencia de la Corte Suprema sobre la doctrina de los actos propios en materia laboral”, en Estudios Laborales, número 4, 2009, AbeledoPerrot, Santiago de Chile, 2010, pp. 37-53; Marzi Muñoz, Daniela Beatriz, "Alteración por la doctrina jurisprudencial del concepto de remuneración para efectos indemnizatorios, en un escenario de 18 años sin reformas legales”, en Estudios Laborales, número 4, 2009, AbeledoPerrot, Santiago de Chile, 2010, pp. 55-68; y los demás estudios publicados en Estudios Laborales, número 4, 2009, AbeledoPerrot, Santiago de Chile, 2010. 
tenor descriptivo. La exposición finaliza con la explicitación de algunas conclusiones de tinte valorativo frente a los resultados obtenidos.

\section{Marco CONCEPTUAL}

\section{Conceptos de empleador y trabajador}

Como se sabe, el artículo $3^{\circ}$ del Código del Trabajo entrega los conceptos de empleador y de trabajador. A partir de la definición del primero, los requisitos que deben concurrir para que un sujeto tenga la calidad de empleador son los siguientes: que se trate de una persona natural o jurídica, que utilice los servicios de una o más personas naturales y que estos servicios se presten en virtud de un contrato de trabajo ${ }^{4}$. Por su parte, tiene la calidad de trabajador, siempre de conformidad con lo dispuesto en el referido artículo $3^{\circ}$, quien cumple con los siguientes requisitos: que se trate de una persona natural, que preste servicios personales, que lo haga bajo subordinación y que preste tales servicios en virtud de un contrato de trabajo 5 .

Pues bien, para efectos del presente trabajo las expresiones empleador y trabajador tendrán un significado más amplio. Se entenderá por empleador y por trabajador no solo a quien efectivamente cumple los requisitos respectivamente mencionados, sino también a aquel sujeto respecto del cual se pretende una declaración judicial de que los cumple. Por tanto, si en definitiva la respectiva resolución judicial rechaza admitir que entre las partes del proceso existe un contrato de trabajo, igualmente se considerará trabajador a quien prestaba los servicios y empleador a quien los recibía.

Estos conceptos "ampliados" se justifican en que en algunos de los juicios laborales que dan lugar a los recursos de unificación de jurisprudencia analizados en la presente investigación lo debatido es, precisamente, si quien presta los servicios tiene la calidad de trabajador y quien los recibe la de empleador en los términos a que se refiere el artículo $3^{\circ}$ del Código del Trabajo.

\section{Clases de empleador}

Desde hace algunas décadas se viene produciendo un fenómeno que la doctrina denomina la "huida del Derecho público" por parte de la Administración del Estado.

\footnotetext{
${ }^{4}$ En el mismo sentido, ver Melis, C., y Sáez, F., El contrato individual de trabajo en los dictámenes de la Dirección del Trabajo, LegalPublishing, Santiago de Chile, tercera edición, 2011, p. 9. Sergio Gamonal y Caterina Guidi coinciden con los tres requisitos mencionados, aunque añaden otros dos relativos a las potestades del empleador y a sus restricciones derivadas de los derechos fundamentales de los trabajadores. Al respecto ver Gamonal, S., y Guidi, C., Manual del contrato de trabajo, AbeledoPerrot (LegalPublishing), Santiago de Chile, 2012, pp. 15 y 16.

${ }^{5}$ En similar sentido Lanata, G., Contrato individual de trabajo, AbeledoPerrot (LegalPublishing), Santiago de Chile, 2010, pp. 17 y 18. Se debe hacer presente que la autora menciona como cuarto requisito la existencia de subordinación y, en consecuencia, ajenidad, en lugar de aludir al contrato de trabajo.
} 
Dicho fenómeno se aplica bajo dos modalidades diversas: la adopción de formas jurídicas propias de las regulaciones del Derecho civil y mercantil y la aplicación el Derecho privado dentro de formas institucionales de Derecho público ${ }^{6}$. En lo que aquí interesa, la aplicación de aquellas modalidades ha provocado que las normas de carácter laboral, esto es, las incluidas en el Código del Trabajo y en sus normas complementarias, regulen a quienes prestan servicios bajo subordinación para instituciones del Estado, en un ámbito que tradicionalmente se regulaba mediante estatutos propios del Derecho administrativo. De este modo, resulta posible distinguir entre los empleadores al Fisco y a los particulares.

Se entiende por Fisco como empleador a las entidades a que se refiere el inciso segundo del artículo $1^{\circ}$ de la Ley 18.575, sobre Bases Generales de la Administración del Estado ${ }^{7}$, incluidas las corporaciones de Derecho privado creadas por las municipalidades para la administración de los servicios de educación y salud. Por otra parte, son empleadores particulares todos los demás sujetos que no tienen la calidad de Fisco en los términos recién explicados, de modo que se incluyen, por ejemplo, las notarías, archiveros judiciales y conservadores de bienes raíces.

Para determinar la clase de empleador de que se trata en cada caso laboral, por regla general se atiende a quien contrató los servicios del trabajador. La única excepción se refiere al caso en que se intenta determinar el alcance de la responsabilidad de la empresa principal cuando demandan los trabajadores de la empresa contratista. En este caso se considera empleador a efectos del presente estudio a la empresa principal. Esto se debe a que son las pretensiones de esta última los que en definitiva se están debatiendo bajo el problema jurídico mencionado.

\section{Significado de resolver a favor de una de las partes}

El recurso de unificación de jurisprudencia es un medio de impugnación extraordinario que procede en contra de las sentencias pronunciadas por las Cortes de Apelaciones conociendo de los recursos de nulidad ${ }^{8}$. Aunque no se expresa directamente en la regulación del instituto procesal, se ha entendido que debe ser deducido por aquel a quien causa agravio la resolución recurrida ${ }^{9}$. La Corte Suprema puede, como es obvio, acoger

${ }^{6}$ Restrepo Medina, M. A. "La adecuación del Derecho administrativo al Estado contemporáneo", en Estudios Socio-Jurídicos, Bogotá, vol. 4, Nº 2, 2002, p. 138.

${ }^{7}$ Las entidades a que se refiere el artículo $1^{\circ}$, inciso segundo, de la Ley 18.575 son las siguientes: los Ministerios, las Intendencias, las Gobernaciones y los órganos y servicios públicos creados para el cumplimiento de la función administrativa, incluidos la Contraloría General de la República, el Banco Central, las Fuerzas Armadas y las Fuerzas de Orden y Seguridad pública, los gobiernos regionales, las municipalidades y las empresas públicas creadas por ley.

${ }^{8}$ En similar sentido, Thayer, W., y Novoa, P., Manual de Derecho del trabajo, Jurídica de Chile, Santiago de Chile, tomo IV, reimpresión de la quinta edición, 2014, p. 202.

${ }^{9}$ Lanata, G., El sistema de recursos en el proceso laboral chileno, AbeledoPerrot y Thomson Reuters, Santiago de Chile, segunda edición, 2011, pp. 259 y 268, con cita de jurisprudencia que respalda esta exigencia. 
o rechazar el recurso ${ }^{10}$. En el primer caso debe dictar acto continuo y sin nueva vista, pero separadamente, la sentencia de reemplazo en unificación de jurisprudencia (artículo 483-C, inciso segundo, del Código del Trabajo).

Las opciones de acoger o rechazar el recurso y la obligación de dictar sentencia de reemplazo ha generado que, en la práctica, la Corte Suprema dicte una, dos o tres sentencias frente a un mismo recurso. Esto no depende de la necesidad de unificar la jurisprudencia, como podría suponerse a partir de los objetivos de este medio de impugnación. Lejos de ello, la cantidad de sentencias dependen de si la Corte Suprema coincide o no con lo resuelto por la Corte de Apelaciones y por el juzgado de la instancia.

A partir de tales precisiones resulta posible explicar que el máximo tribunal favorece la posición del empleador en tres casos. Primero, cuando se limita a rechazar el recurso de unificación de jurisprudencia deducido por el trabajador, pues coincide con el criterio de la Corte de Apelaciones ${ }^{11}$. Segundo, cuando acoge el recurso de unificación deducido por el empleador y acto seguido rechaza el de nulidad interpuesto por el trabajador, pues diverge del criterio de la Corte de Apelaciones y coincide con el juzgado ${ }^{12}$. Y tercero, cuando acoge el recurso de unificación deducido por el empleador, acto seguido acoge el de nulidad deducido por esta misma parte y, como consecuencia, inmediatamente reemplaza la sentencia del juzgado de instancia, pues diverge de lo sostenido tanto por la Corte como por el juzgado ${ }^{13}$. Inversamente, la Corte Suprema se inclina a favor de lo pretendido por el trabajador en los escenarios opuestos a los recién descritos.

\section{Metodología}

Para explicar la metodología empleada es necesario distinguir dos etapas en el proceso de investigación. La primera de ellas consistió en definir el universo de recursos de unificación de jurisprudencia que serían analizados. La segunda etapa tuvo por finalidad determinar a cuál de las partes en juicio, esto es, empleador o trabajador, favoreció la decisión recaída en los mismos.

\section{Determinación del universo de recursos a analizar}

La metodología utilizada para definir el universo de recursos de unificación de jurisprudencia que serían analizados se explica al hilo de los diversos pasos seguidos para cumplir esta primera etapa.

${ }^{10} \mathrm{La}$ posibilidad de acoger el recurso se establece de manera expresa en el artículo 483-C. La opción del rechazo no se contempla sino implícitamente, mediante interpretación a contrario sensu.

${ }^{11}$ A modo de ejemplo pueden verse Corte Suprema, Tudela con Corporación Municipal de Servicio y Desarrollo de Maipú, rol 70-2011.

${ }^{12}$ A modo de ejemplo puede verse Corte Suprema, Cabello con Cáceres, rol 3488-2011.

${ }^{13}$ A modo de ejemplo puede verse Corte Suprema, Salgado con Toledo y otros, rol 8316-2010. 
a) Identificación de los recursos deducidos en el período establecido para la investigación. Este paso se cumplió por dos vías paralelas. De un lado, se solicitó a la Unidad de Computación y Estadísticas de la Corte Suprema la información relativa a los recursos de unificación de jurisprudencia ingresados a dicho tribunal entre el 30 de marzo de 2008 y el 29 de marzo de 2012. Por otra parte, se revisó la información proveída por la página web del Poder Judicial relativa al ingreso diario de tales recursos en el período mencionado ${ }^{14}$.

b) Obtención de las sentencias recaídas en los recursos de unificación de jurisprudencia deducidos en el período en estudio. Este paso se cumplió descargando de la página web del Poder Judicial la totalidad de las sentencias recaídas en los recursos de unificación de jurisprudencia identificados de conformidad con lo expresado en el paso anterior. De este modo se generó una base de datos en el que se asignó un archivo a cada recurso, incluyéndose en el mismo una, dos o tres sentencias según correspondiera.

c) Selección de recursos que serán objeto de análisis. De conformidad con la regulación legal, un recurso de unificación de jurisprudencia laboral puede ser objeto de diversas salidas procesales. En efecto, se le puede declarar desierto ${ }^{15}$, no presentado $^{16}$, inadmisible ${ }^{17}$, o desistido ${ }^{18}$, o puede ser sentenciado. Solo aquellos recursos que se encuentran en esta última situación, es decir, aquellos en que la Corte Suprema ha decidido acoger o rechazar el recurso, son útiles para la presente investigación.

\section{Determinación de a qué parte favoreció lo resuelto}

Según se advirtió al presentar el marco conceptual de este trabajo, la Corte Suprema puede emitir una, dos o tres sentencias al pronunciarse acerca de un determinado recurso

${ }^{14}$ No fue posible contrastar las dos vías señaladas con un registro físico de los recursos de unificación ingresados en el período en estudio (libro de ingreso de causas). Esto se debe a que la Corte Suprema ya no utiliza estos soportes físicos para dejar constancia de los ingresos, sino soportes informáticos.

${ }^{15}$ El recurso se declara desierto si el recurrente no se hace parte ante la Corte Suprema dentro de quinto día contado desde que se reciben los autos en la Secretaría de dicha Corte (artículo 432 del Código del Trabajo, respecto de los artículos 200 y 201 del Código de Procedimiento Civil).

${ }^{16}$ El recurso se tiene por no presentado si no se acompañan tantas copias cuantas sean las partes a las que deba notificarse la providencia que en él recaiga o si existe disconformidad sustancial entre el original y las copias, y la parte no cumple el apercibimiento del tribunal, en orden a acompañar las copias dentro de tercero día (artículo 432 del Código del Trabajo, en relación con el artículo 31 del Código de Procedimiento Civil).

${ }^{17}$ La sala especializada de la Corte Suprema debe declarar la inadmisibilidad del recurso si no se presenta ante la Corte de Apelaciones respectiva, se interpone fuera del plazo fatal de quince días establecido al efecto, carece de fundamentos, no contiene una relación precisa de las distintas interpretaciones respecto de la materia de Derecho objeto del juicio sostenidas en diversos fallos emanados de los tribunales superiores o no se acompañan las sentencias que se invocan como fundamento (artículo 483-A, inciso séptimo, del Código del Trabajo).

${ }^{18} \mathrm{E} l$ recurso se tiene por desistido si la parte retira el recurso, lo que extingue la acción deducida (artículo 432 del Código del Trabajo, en relación con los artículos 148 y 150 del Código de Procedimiento Civil). 
de unificación de jurisprudencia, dependiendo de si coincide o diverge de lo decidido por la Corte de Apelaciones y por el juzgado de la instancia. De este modo, la metodología empleada para determinar a qué parte favoreció lo resuelto por el máximo tribunal exigió analizar el contenido de la o las sentencias recaídas en cada recurso en los que se acogió o rechazó el referido instituto procesal. De este modo resultó posible alcanzar el objetivo planteado por la presente investigación, consistente en determinar si la Corte Suprema de manera preferente otorga tutela a los intereses de los empleadores.

Como producto adicional, no considerado en los objetivos originales de la investigación, fue posible evaluar el grado de sintonía de la Corte Suprema con el resto de los tribunales del país, en lo relativo a las materias de Derecho objeto de los juicios laborales que dieron lugar a los recursos de unificación de jurisprudencia analizados. Para este efecto se atendió a lo expresado en la parte expositiva de las respectivas sentencias acerca del modo en que el juzgado de instancia y la Corte de Apelaciones resolvieron el caso objeto del recurso. En particular se consideró qué parte ejerció la acción procesal y qué parte dedujo a continuación el recurso de nulidad.

\section{REsultados}

En la presente investigación interesan únicamente aquellos recursos de unificación de jurisprudencia en los que la Corte Suprema se pronunció sobre las pretensiones de las partes. Por ello, la exhibición de los resultados exige expresar, de forma previa, las cifras que arrojó la metodología aplicada para determinar ese universo.

\section{Determinación del universo de recursos a analizar}

En el desarrollo de cada uno de los pasos tendentes a determinar el universo de recursos de unificación de jurisprudencia que sería objeto de análisis se fueron presentando, escalonadamente, los resultados que a continuación se explican.

Ante todo se debe hacer presente que en la identificación de los recursos elevados a la Corte Suprema entre el 30 de marzo de 2008 y el 29 de marzo de 2012 fue posible encontrar una discrepancia entre la información proveída por la Unidad de Computación y Estadísticas de dicho tribunal y los antecedentes disponibles en la página web del Poder Judicial. Mientras la primera registra 1.047 recursos, la segunda da cuenta de cinco más ${ }^{19}$. La revisión de esos cinco casos permitió confirmar que efectivamente se trataba

\footnotetext{
${ }^{19}$ Los cinco recursos de unificación de jurisprudencia que constan en la página web del Poder Judicial y que no se registran en la información proveída por la Unidad de Computación y Estadísticas de la Corte Suprema son los siguientes: Corte Suprema, Gilberto Santana Díaz con Víctor Fugielle y Cía. Ltda., rol 51642008; Corte Suprema, Juan Carlos Ramírez Cortés con Pietro Depetris e Hijos y Cía. Ltda., rol 7355-2008; Corte Suprema, Jaime Ledesma Herrera y otros con Velásquez S.A. y Anglo América S.A., rol 1651-2009; Corte Suprema, Ocaranza Godoy Waldo con Velásquez S.A. y Anglo América S.A., rol 3158-2009; y Corte Suprema, Águila con Servicios Forestales S.A., rol 9301-2009. En todo caso, en ninguno de ellos recayó un pronunciamiento de fondo por parte de la Corte Suprema, esto es, acogiendo o rechazando el recurso.
} 
de recursos de unificación de jurisprudencia laboral y, por tanto, el total ingresado en el período en estudio alcanzó a 1.052. Dos de ellos se acumularon, recayendo sobre ambos una misma decisión. Por tanto la cifra disminuyó a 1.051.

La clasificación de los recursos de unificación atendiendo a la salida procesal de que fueron objeto permite advertir que solo 227 fueron resueltos mediante una decisión de acogerlo o rechazarlo. Del resto, la mayoría fue declarado inadmisible, mientras un número relativamente menor fue declarado desierto o no presentado. La siguiente tabla muestra tales datos en términos absolutos y porcentuales:

\begin{tabular}{lcccccr}
\hline Salida procesal & Desierto & No presentado & Inadmisible & Desistido & Sentenciado & Total \\
\hline Número. & 166 & 44 & 596 & 18 & 227 & 1.051 \\
\hline Porcentaje $^{1}$ & 15,8 & 4,2 & 56,7 & 1,7 & 21,6 & 100 \\
\hline
\end{tabular}

Fuente: Elaboración propia.

En adelante interesan solamente aquellos recursos de unificación de jurisprudencia que fueron acogidos o rechazados, esto es, los 227 incluidos en la categoría "sentenciados". No obstante, el análisis de las sentencias recaídas en tales recursos permitió advertir tres circunstancias que exigen redefinir el universo a analizar.

La primera de aquellas circunstancias consiste en que un grupo de los 227 recursos no contenía un pronunciamiento respecto de las pretensiones de las partes. En lugar de ello, los rechazaban por razones relacionadas con la admisibilidad de los mismos. De este modo, generaban una especie de "inadmisibilidad retardada" que no contempla el proceso laboral $^{20}$. De los 227 recursos mencionados, 61 se encuentran en tal situación. Estos 61 recursos serán excluidos de los análisis que siguen, pues, según se ha dicho, en ellos no existe un pronunciamiento respecto de las pretensiones de las partes y, por tanto, no colaboran en forma alguna al cumplimiento de los objetivos de esta investigación. De este modo, al descontar a los 227 recursos de unificación de jurisprudencia los 61 en los que no existe pronunciamiento relativo a las pretensiones de las partes, el universo que será objeto de análisis se reduce a 166 causas.

La segunda de las circunstancias en cuestión consiste en que en dos de los 166 recursos de unificación de jurisprudencia referidos no se plantea un problema entre empleador y trabajador. En lugar de ello, se litiga en torno a materias del ámbito del Derecho de la

${ }^{20}$ En estos casos los recursos de unificación fueron desestimados, por ejemplo, porque los hechos que fundan el recurso son distintos respecto de aquellos contenidos en las sentencias acompañadas; en las sentencias acompañadas existe el mismo lineamiento jurisprudencial contenido en el recurso de nulidad impugnado; el recurso de nulidad no se pronuncia acerca del debate de fondo; existe contradicción entre los fundamentos de Derecho en los que se sustenta el recurso de unificación, en relación con el pronunciamiento que en definitiva se solicita a la Corte Suprema; y las sentencias que se acompañan para fundar el recurso no se pronuncian respecto de la materia de derecho que se pretende unificar. 
seguridad social ${ }^{21}$. Como asuntos de esta naturaleza no colaboran al cumplimiento del objetivo de este trabajo, deben ser igualmente excluidos. De este modo, el universo de recursos a analizar se reduce de 166 a 164 .

La tercera circunstancia que se debe mencionar no modifica el universo de 164 recursos de unificación de jurisprudencia a analizar, sino la cantidad de pronunciamientos que contienen los mismos. Esto se debe a que en cuatro de ellos existe decisión acerca de dos pretensiones deducidas por las partes y no respecto de una sola ${ }^{22}$. En consecuencia, si bien los recursos a considerar son 164 , el total de pronunciamientos recaídos en aquellos se eleva a 168 . De este modo, esta es la cifra que en adelante se considerará para los análisis que se realizan.

\section{Posición de la Corte Suprema frente a las pretensiones de las partes}

Según se ha advertido al exponer las tres circunstancias que sucesivamente modifican el universo que será objeto de análisis, en adelante no se aludirá a los 164 recursos de unificación de jurisprudencia que constituyen el universo de casos en análisis, sino a los 168 pronunciamientos emitidos por la Corte Suprema en esos 164 recursos. Esto se debe a que cada uno de esos 168 pronunciamientos expresa una opción de la Corte Suprema frente a las pretensiones de empleador y trabajador.

Pues bien, el dato más general arroja que 159 de los 168 pronunciamientos emitidos por la Corte Suprema en los 164 recursos de unificación de jurisprudencia que constituyen el universo en análisis fueron favorables al empleador. Los 9 restantes se inclinaron a favor del trabajador. En términos porcentuales, esto significa que en el 95,2\% de los casos la Corte Suprema acogió las pretensiones del primero y solo en el $4,8 \%$ acogió las del segundo.

El análisis de los datos desde el punto de vista de las materias de Derecho objeto del juicio puede resultar menos impactante. Los 168 pronunciamientos emitidos por la Corte Suprema en los 164 recursos de unificación de jurisprudencia objeto del presente estudio trataron, en total, 43 de aquellas materias. En 35 de esos universos la Corte Suprema sentenció de manera sistemática y uniforme a favor del empleador. En 7 de esos universos falló a favor del trabajador de manera igualmente sistemática y uniforme. El último universo se componía de 3 causas, en dos de las cuales se inclinó a favor del primero y en una a favor del segundo. De este modo, en el $81,4 \%$ de estos universos

${ }^{21}$ Las dos causas en las que se tratan pretensiones de índole previsional y no laboral son las siguientes: Corte Suprema, Corvera con Instituto de Previsión Social, rol 6246-2010, y Corte Suprema, Rodríguez con Instituto de Previsión Social, rol 4790-2011.

${ }^{22}$ Las cuatro causas que cuentan con dos pronunciamientos por parte de la Corte Suprema debido a que tratan dos materias de Derecho cada una de ellas, son las siguientes: Corte Suprema, Osses y otros con AFP Habitat S.A., rol 470-2011; Corte Suprema, Parra y Otros con Ilustre Municipalidad de Temuco, rol 78712011; Corte Suprema, Peralta con Corporación Municipal de Edu., Salud y Atenc. De Menores de Puente Alto, rol 10.266-2011; y Corte Suprema, Kerbermhard con Recaudación y Cobranzas S.A., rol 9579-2011. 
fue acogida la pretensión del empleador, en el 16,3\% las del trabajador y en 2,3\% las de uno u otro.

Las preferencias de la Corte Suprema también pueden ser analizadas desde el punto de vista de la clase de empleador. De los 168 pronunciamientos de la Corte Suprema recaídos en los 164 recursos de unificación de jurisprudencia en análisis, en 79 el empleador fue el Fisco y en 77 de ellos se acogió la pretensión del ente público. En 89 pronunciamientos la contraparte del trabajador fue un particular y en 82 de ellos el caso fue resuelto en favor de este último. En términos porcentuales las pretensiones del empleador fueron acogidas en $97,5 \%$ de los pronunciamientos cuando se trató del Fisco y en $92,1 \%$ cuando se trató de un particular.

\section{La Corte Suprema frente a las Cortes de Apelaciones y los juzgados de instancia}

Las posiciones asumidas por la Corte Suprema frente a los problemas jurídicos de índole laboral que se le presentaron en el período en estudio pueden ser evaluadas no solo en sí mismas, como se ha hecho en el apartado anterior. Resulta también posible contrastar estos resultados con las posiciones sostenidas por las Cortes de Apelaciones al resolver los mismos casos, antes de que fueran decididos mediante el recurso de unificación de jurisprudencia laboral.

Para estos efectos conviene recordar que el universo en análisis está constituido por 168 pronunciamientos recaídos en 164 recursos de unificación de jurisprudencia. Pues bien, 35 de ellos fueron favorables al empleador y 133 al trabajador cuando el mismo asunto debió ser resuelto por alguna de las 17 Cortes de Apelaciones del país. De este modo, las pretensiones del empleador fueron acogidas por las Cortes de Apelaciones en el 20,8\% de los casos y las del trabajador en el 79,2\%.

A la anterior constatación se puede añadir la observada al contrastar las resoluciones de la Corte Suprema con las decisiones emitidas por los tribunales de instancia. En 51 de los 168 pronunciamientos que constituyen el universo en estudio, la materia de Derecho fue resuelta a favor del empleador por parte de los juzgados con competencia laboral. En 116 pronunciamientos resultó favorecido el trabajador en la respectiva sentencia de instancia. En uno de los casos el juzgado con competencia laboral no se pronunció concerniente a la materia de Derecho que luego fue decidida en las Cortes ${ }^{23}$. De este modo, las pretensiones del primero fueron acogidas en 30,4\% de los casos por parte de la sentencia definitiva de única instancia, mientras que las del segundo lo fueron en el $69,0 \%$. El 0,6\% restante corresponde al caso sin pronunciamiento.

Junto con esos datos generales es posible exponer algunos resultados en los que las decisiones de la Corte Suprema se contrastan con las de los demás tribunales, por materia de Derecho objeto del juicio. Al respecto se debe recordar que los 168

${ }^{23}$ Se trata de la siguiente causa: Corte Suprema, Osses y otros con AFP Habitat S.A., rol 470-2011, en la que se debate si determinar el carácter diario de la comisión por suscripción es una cuestión fáctica o jurídica. Relativo a este extremo solo existe pronunciamiento de la Corte de Santiago y de la Corte Suprema, pero no del juzgado de instancia. 
pronunciamientos emitidos por el máximo tribunal en los 164 recursos de unificación objeto del presente estudio se distribuyen en 43 universos, cada uno de ellos se refiere a una de tales materias. En lo que sigue se explicita únicamente dicho contraste en los cuatro universos con mayor número de pronunciamientos, que en conjunto reúnen 96 de aquellas 168 decisiones $^{24}$.

Una de esas cuatro materias es la procedencia de la sanción establecida en el artículo 162 cuando la existencia de la relación laboral ha sido establecida por sentencia judicial. En los 9 casos que trataron de este asunto la Corte Suprema se inclinó a favor de las pretensiones del empleador. Por el contrario, la totalidad de las Cortes de Apelaciones que conocieron de estos mismos casos (La Serena, Valparaíso, Santiago, Rancagua y Talca) y de los juzgados de instancia (con excepción de uno) se pronunciaron a favor de la pretensión del trabajador en orden a que resultaba procedente aplicar dicha sanción si las cotizaciones previsionales no estaban al día 25 .

Otra de esas materias es la procedencia del beneficio establecido en el inciso primero del artículo 45 (semana corrida) a los trabajadores con remuneración mixta, esto es, en parte fija y en parte variable. En los 20 casos en que se trató de este asunto la Corte Suprema se pronunció a favor de las pretensiones del empleador. Por el contrario, las Cortes de Apelaciones (Iquique, Santiago, San Miguel, Concepción, Temuco y Valdivia) y los juzgados de instancia que conocieron de estos mismos casos fallaron a favor de la posición del trabajador en 17 y 15 casos, respectivamente ${ }^{26}$.

${ }^{24}$ La baja cantidad de sentencias recaídas en cada una de las otras materias de Derecho objeto del juicio torna menos interesante explicitar el contraste entre las posiciones sostenidas en aquellas por la Corte Suprema, por una parte, y por las demás Cortes y los juzgados de instancia, por otra.

${ }^{25}$ Las nueve causas son las siguientes: Corte Suprema, Núñez con Sociedad Contractual Minera Tambillos, rol 852-2010; Corte Suprema, Villanueva con Fisco de Chile Armada de Chile, rol 5447-2010; Corte Suprema, Araya con Bodega La Esperanza Viñedos Errázuriz Ovalle S.A., rol 10120-2010; Corte Suprema, Soza con Televisión Nacional de Chile, rol 205-2011; Corte Suprema, Acosta y Otros con Sociedad Depetris Deflorian Hnos. Ltda., rol 116-2011; Corte Suprema, Araya con Monte Nevado Ingeniería y Otros, rol 9375-2010; Corte Suprema, Orrego con Empresa Periodística La Cuarta S.A., rol 8989-2011; Corte Suprema, Olivares con Pontificia Universidad Católica de Chile, rol 1855-2012; y Corte Suprema, Riquelme con Pontificia Universidad Católica de Chile Corporación de Televisión, rol 1681-2012.

${ }^{26}$ Las veinte causas son las siguientes: Corte Suprema, A.F.P. Provida con Román, rol 4751-2010; Corte Suprema, Gómez con ING AFP Capital S.A., rol 6019-2010; Corte Suprema, Prado con ING AFP Capital S.A., rol 6552- 2010; Corte Suprema, Reyes con A.F.P. Próvida S.A., rol 6101- 2010; Corte Suprema, Cabrera con A.F.P. Próvida S.A., rol 6114-2010; Corte Suprema, Pereira con A.F.P. Próvida S.A., rol 61152010; Corte Suprema, Cáceres con ING AFP Capital S.A., rol 6777-2010; Corte Suprema, Monroy y otra con AFP Hábitat S.A., rol 6450-2010; Corte Suprema, Rencoret y Otro con AFP Provida S.A., rol 72082010; Corte Suprema, Caro y Otros con AFP Provida S.A., rol 6932-2010; Corte Suprema, Sindicato de Trabajadores de la AFP Provida S.A. con AFP Provida S.A., rol 1117-2011; Corte Suprema, Valenzuela con AFP Capital S.A., rol 8860-2010; Corte Suprema, Osses y Otros con AFP Habitat S.A., rol 470-2011; Corte Suprema, Alarcón con Administradora de Fondos de Pensiones Capital S.A. rol 1863-2011; Corte Suprema, Sindicato Unificado de Trabajadores de Isapre Banmédica S.A. con Isapre Banmédica S.A., rol 2739-2011; Corte Suprema, Aravena y Otros con VTR Global Com S.A., rol 8788-2011; Corte Suprema, Gonzáles y Otros con AFP Provida S.A., rol 8322-2011; Corte Suprema, Parada con AFP Capital S.A., rol 10713-2011; Corte Suprema, Kerbernhard con Recaudación y Cobranzas S.A., rol 9579-2011; y Corte Suprema, Irazzoky con Comercial Rey S.A., rol 11873-2011. 
La tercera de estas materias es la inclusión de asignaciones que no constituyen remuneración en el concepto última remuneración mensual del artículo 172 del Código del Trabajo. En los 16 casos en que se trató de este asunto la Corte Suprema rechazó incorporar dichas asignaciones. En sentido exactamente inverso, la totalidad de las Cortes que conocieron de estos mismos casos (Valparaíso, Santiago, San Miguel, Concepción y Puerto Montt) y de los juzgados de instancia (con excepción de uno) resolvieron lo contrario, admitiendo dichas asignaciones en la referida base de cálculo ${ }^{27}$.

La última de estas cuatro materias es la procedencia de la indemnización por años de servicios establecida en el artículo $2^{\circ}$ transitorio de la Ley 19.070, respecto de profesionales de la educación que renunciaron voluntariamente ajustándose a las exigencias del artículo $2^{\circ}$ transitorio de la Ley 20.158. La Corte Suprema resolvió los 51 casos en que se trató este asunto a favor del empleador, negando la procedencia de dicha indemnización. Las Cortes de Apelaciones (Iquique, Valparaíso, Santiago, San Miguel, Talca, Concepción, Valdivia y Puerto Montt) y los juzgados de instancia acogieron la posición contraria, esto es, la sostenida por el trabajador, en $38(74,5 \%)$ y $23(45,1 \%)$ de esos casos, respectivamente ${ }^{28}$.

${ }^{27}$ Las dieciséis causas son las siguientes: Corte Suprema, Vega con Análisis y Servicios S.A., rol 96032009; Corte Suprema, Alegría con Laboratorio Koni Cofarm S.A., rol 4196-2010; Corte Suprema, Alarcón con Análisis y Servicios S.A, rol 6074-2010; Corte Suprema, Flores y otro con Servicios Prosegur Limitada rol 5881-2010; Corte Suprema, Zúñiga con Transportes Aéreos del Mercosur S.A., rol 7362-2010; Corte Suprema, Fernández con Inesa Chile S.A. rol 8155-2010; Corte Suprema, Monsalve con Sociedad Educacional ArabPerezLtda rol 3169-2011; Corte Suprema, Berríos con Pullman cargo rol 3168-2011; Corte Suprema, Rodríguez con Inversiones Alsacia S.A, rol 4735-2011; Corte Suprema, Gallardo con Red Capacita S.A., rol 5843-2011; Corte Suprema, Campusano con AFP Planvital S.A, rol 8504-2011; Corte Suprema, Caro con Envases Del Pacífico S.A., rol 9242-2011; Corte Suprema, Azócar con Sociedad Comercial Wingel Ltda., rol 9838-2011; Corte Suprema, Becker con Premium Nutregg S.A., rol 361-2012; Corte Suprema, Loyola con Compass Catering S.A., rol 208-2012; y Corte Suprema, Ponce con Distribuidora de Industrias Nacionales S.A DIN, rol 11655-2011.

${ }^{28}$ Las cincuenta y un causas son las siguientes: Corte Suprema, Mejías con Municipalidad de Valdivia, rol 8809-2009; Corte Suprema, Peralta con Municipalidad de Chiguayante, rol 9024-2009; Corte Suprema, Núñez Sonia y Otros con Ilustre Municipalidad de Lanco, rol 627-2010; Corte Suprema, Alarcón con Municipalidad de San Pedro de la Paz, rol 212-2010; Corte Suprema, Ayala con Corporación Municipal de Desarrollo Social de Iquique, rol 7930-2009; Corte Suprema, Cea y Otros con I. Municipalidad de Coronel, rol 1167-2010; Corte Suprema, Machuca con Ilustre Municipalidad de San Pedro de la Paz, rol 171-2010; Corte Suprema, Ramírez con Ilustre Municipalidad de Hualpén, rol 915-2010; Corte Suprema, Candia con I. Municipalidad de Yumbel, rol 1346-2010; Corte Suprema, Castro y Otros con Municipalidad de Colbún, rol 1984-2010; Corte Suprema, Espinosa con I. Municipalidad de Linares, rol 3357-2010; Corte Suprema, González con Ilustre Municipalidad de los Ángeles, rol 2975-2010; Corte Suprema, Sepúlveda con Ilustre Municipalidad de Talcahuano, rol 1312-2010; Corte Suprema, Uribe y Otro con I. Municipalidad de Paillaco, rol 19852010; Corte Suprema, Bustamante y Otro con I. Municipalidad de Parral, rol 1584-2010; Corte Suprema, Pérez y Otros con I. Municipalidad de Mariquina, rol 2419-2010; Corte Suprema, Avendaño y Otros con Ilustre Municipalidad de Curepto, rol 1349-2010; Corte Suprema, Ávila y Otros con Ilustre Municipalidad de Parral, rol 1954-2010; Corte Suprema, Encina y Otros contra I. Municipalidad de Yerbas, rol 1586-2010; Corte Suprema, Alejandrina con Ilustre Municipalidad de Talca, rol 1392-2010; Corte Suprema, Corvalán con Ilustre Municipalidad de Talca, rol 1345-2010; Corte Suprema, Libis con Municipalidad de Valdivia, rol 1639-2010; Corte Suprema, Lienlaf Marilaf y Otras con I. Municipalidad de Mariquina, rol 629-2010; Corte Suprema, Medel con Ilustre Municipalidad de Talca, rol 1489-2010; Corte Suprema, Rivera con 


\section{CONCLUSIONES}

La primera y más obvia de las conclusiones de la presente investigación es que se ha confirmado la hipótesis planteada al inicio. En efecto, la Corte Suprema ha favorecido mayoritariamente las pretensiones de los empleadores al momento de resolver los recursos de unificación de jurisprudencia laboral deducidos en el período en estudio. Esto ha ocurrido, según se expresó, en el 95,2\% de los casos.

Una segunda conclusión es que la desmesurada preferencia de la Corte Suprema por las pretensiones del empleador es relativamente estable entre las diversas clases de empleador. En efecto, esta notable inclinación alcanzó 97,5\% de los casos cuando se trató del Fisco y 92,1\% cuando se trató de un empleador privado. La ligera diferencia, cercana al 5\%, no obsta a esta segunda conclusión.

Una tercera conclusión es que la Corte Suprema se encuentra desconectada de las orientaciones jurisprudenciales del resto de los tribunales del país, al menos en las materias de Derecho que han sido objeto de los 164 recursos de unificación analizados. Lo más interesante en este punto es que, por el contrario, existe una elevada coincidencia doctrinaria entre los juzgados de instancia con competencia laboral y las Cortes de Apelaciones del país. En efecto, mientras los primeros acogieron las pretensiones de los trabajadores en 69,0\% de los casos, las segundas lo hicieron en 79,2\%. Conviene advertir que esta disonancia de la Cuarta Sala de la Corte Suprema es aún más extraña frente a juzgados de instancia que, en importante número, tienen competencia especializada.

Una cuarta conclusión se relaciona con las materias de Derecho objeto del juicio. $\mathrm{Al}$ respecto es posible advertir que en ciertas materias (pocas, por cierto) existe una elevada dispersión jurisprudencial entre juzgados de instancia y Cortes de Apelaciones. Es

\footnotetext{
Ilustre Municipalidad de Talca, rol 1491-2010; Corte Suprema, San Martín con Ilustre Municipalidad de Talcahuano, rol 2454-2010; Corte Suprema, Agurto y Otros con Ilustre Municipalidad de Cauquenes, rol 3352-2010; Corte Suprema, Inocencio con I. Municipalidad de Quillota, rol 3609-2010; Corte Suprema, Arancibia y Otros con Ilustre Municipalidad de Quillota, rol 3488-2010; Corte Suprema, Moya con Ilustre Municipalidad de Linares, rol 3718-2010; Corte Suprema, Muena y Otros con Municipalidad de Linares, rol 1959-2010; Corte Suprema, Concha con Ilustre Municipalidad de Constitución, rol 2578-2010; Corte Suprema, Silva con Municipalidad de Huechuraba, rol 3991-2010; Corte Suprema, Herrera con Corporación de Desarrollo Social, rol 3846-2010; Corte Suprema, Aguilera con I. Municipalidad de Curicó, rol 33582010; Corte Suprema, Corvera con Ilustre Municipalidad de El Bosque, rol 3292-2010; Corte Suprema, Corvera con Ilustre Municipalidad de El Bosque, rol 3293-2010; Corte Suprema, Neira con I. Municipalidad de Hualqui, rol 3013-2010; Corte Suprema, Lorca y Otros con Ilustre Municipalidad de Arauco, rol 50622010; Corte Suprema, Constant y Otros con Ilustre Municipalidad de Lebu, rol 5010-2010; Corte Suprema, Araneda y Otros con Ilustre Municipalidad de los Álamos, rol 5833-2010; Corte Suprema, Fuentez y Otros con Ilustre Municipalidad de Lebu, rol 5011-2010; Corte Suprema, Bravo con Corporación de Desarrollo I. Municipalidad de la Reina, rol 4911-2010; Corte Suprema, Silva con Corporación de Desarrollo Social de Providencia, rol 5835-2010; Corte Suprema, Meza y Otros con Municipalidad de Hualañé, rol 6763-2010; Corte Suprema, Cárcamo con Ilustre Municipalidad de Puerto Montt, rol 5132-2010; Corte Suprema, Canales y otros con I. Municipalidad de San Rosendo, rol 4371-2010; Corte Suprema, Ahumada [esta es la carátula que aparece en la página web del Poder Judicial], rol 7828-2010; Corte Suprema, Mora con Municipalidad de Chiguayante, rol 6973-2010; Corte Suprema, Córdova con Ilustre Municipalidad de Curicó, rol 88592010; y Corte Suprema, Cárdenas con Corporación Municipal de La Florida, rol 10066-2011.
} 
lo que ocurre paradigmáticamente con la procedencia de la indemnización por años de servicios respecto de profesionales de la educación que renunciaron en forma voluntaria a su trabajo. En este caso la intervención de la Corte Suprema aparece justificada con miras a uniformar la jurisprudencia. Sin embargo, hay otros casos en los que todas las Cortes de Apelaciones y los juzgados de instancia (con excepción de uno en cada caso) se pronunciaron a favor de la posición sostenida por el trabajador. Así ocurre con la aplicación de la sanción del artículo 162 si la existencia de la relación laboral se reconoció en la sentencia y con la inclusión de asignaciones que no constituyen remuneración en la base de cálculo de las indemnizaciones. En este caso la Corte Suprema ya no interviene para uniformar la jurisprudencia que, como se ha visto, es uniforme, sino para imponer una interpretación que es contraria a lo unánimemente sostenido por las Cortes de Apelaciones del país y por la generalidad de los tribunales de instancia.

Los datos ofrecidos en el apartado relativo a los resultados y las conclusiones precedentemente ofrecidas generan los siguientes comentarios y una última conclusión.

A estas alturas de la reflexión científica no existen dudas que la aplicación del Derecho no consiste en una simple subsunción de los hechos (premisa menor) en premisas mayores generales y abstractas (las normas). En efecto, y como expresa Rafael De Asís, la "interpretación en el Derecho, cuando es llevada a cabo por determinados operadores jurídicos, posee una función normativa y no meramente recognoscitiva" ${ }^{29}$. Esto significa, en palabras de Luigi Ferrajoli, que la interpretación "siempre es el fruto de una elección práctica respecto de hipótesis interpretativas alternativas" ${ }^{30}$. Este carácter normativo y no meramente recognoscitivo de la interpretación jurídica se debe esencialmente a tres factores: las características del lenguaje jurídico, el compromiso del operador jurídico con el resultado de la interpretación, y la inevitable aplicación de criterios valorativos al interpretar. Acerca de este último factor interesa decir todavía una cosa más.

La interpretación jurídica es una actividad valorativa por parte de quien la realiza. "Es decir, a pesar de que puedan ser descritos criterios y mecanismos jurídicos interpretativos, a la hora de interpretar aparecen también las apreciaciones del intérprete, que tiene que elegir entre posibles significados"31. Esta valoración es inevitable por múltiples razones. Entre ellas puede citarse, por ejemplo, la concepción que mantenga el intérprete sobre el Derecho ${ }^{32}$, la lógica desde la que se justifica la interpretación del

29 De Asís Roig, R., Jueces y normas. La decisión judicial desde el ordenamiento, Marcial Pons, Madrid, 1995, p. 178.

${ }^{30}$ Ferrajoli, L., Derecho y razón. Teoría del garantismo penal, traducción de Perfecto Andrés Ibáñez, Alfonso Ruiz Miguel, Juan Carlos Bayón Mohino, Juan Terradillos Basoco y Rocío Cantarero Bandrés, Trotta, Madrid, tercera edición, 1998, pp. 37 y 38.

31 De Asís Roig, R., Jueces y normas. La decisión judicial desde el ordenamiento, Marcial Pons, Madrid, 1995, p. 182.

32 Sobre el punto, afirma Rafael De Asís: "El proceso interpretativo es claramente valorativo y en él hay presencia de opciones ideológicas, muchas de las cuales parten de la forma en la que se concibe lo jurídico”. Ver Peces-Barba Martínez, G. (con la colaboración de Rafael De Asís Roig, Carlos R. Fernández Liesa y Ángel Llamas Cascón), Curso de derechos fundamentales, Universidad Carlos III de Madrid y Boletín Oficial del Estado, Madrid, primera reimpresión, 1999, p. 573. 
enunciado normativo ${ }^{33}$, la complejidad de los asuntos respecto de los cuales debe recaer la decisión ${ }^{34}$, la inexistencia de enunciados normativos en los que el caso pueda ser subsumido $^{35}$, o la posibilidad de resolver contra enunciado normativo expreso en casos especiales ${ }^{36}$. Es precisamente este carácter valorativo el que provoca que unas mismas disposiciones sean interpretadas de diversa manera y, en consecuencia, se generen distintas soluciones para casos iguales.

Sin embargo, la casi absoluta inclinación de la Cuarta Sala de la Corte Suprema a favor de las pretensiones procesales de los empleadores, en oposición a las tendencias jurisprudenciales del resto de los tribunales del país, no parece solo el resultado de una actividad valorativa. Resolver el 95,2\% de los casos a favor de los empleadores, incluso en materias uniformemente resueltas en sentido contrario por las Cortes de Apelaciones, parece indiciario de una ideología sobre el Derecho del trabajo y sobre la relación entre empleador y trabajador. Una ideología que, seguramente en muchos casos (probablemente en la mayoría, si se consideran las tendencias jurisprudenciales del resto de los tribunales del país), perjudicó legítimos derechos de los trabajadores.

Estas conclusiones evocan las reflexiones de Richard A. Posner, quien, a propósito del giro jurisprudencial que se produjo por el cambio de un Ministro en la Corte Suprema de Estados Unidos, sostuvo que dicho cambio trae a un primer plano la pregunta acerca de cómo los elementos personales y políticos pueden influir en la actividad de juzgar y, con ello, el sentido en que el país está siendo gobernado por los jueces en lugar de por las leyes ${ }^{37}$.

\section{BIBLIOGRAFÍA}

\section{Libros}

Alexy, R., Teoría de la argumentación jurídica, traducción de Manuel Atienza e Isabel Espejo, Centro de Estudios Constitucionales, Madrid, primera reimpresión, 1999.

De Asís Roig, R., Jueces y normas. La decisión judicial desde el ordenamiento, Marcial Pons, Madrid, 1995.

Díaz Méndez, M., El recurso de unificación de jurisprudencia laboral, Libromar, Santiago de Chile, 2014. Ferrajoli, L., Derecho y razón. Teoría del garantismo penal, traducción de Perfecto Andrés Ibáñez, Alfonso Ruiz Miguel, Juan Carlos Bayón Mohino, Juan Terradillos Basoco y Rocío Cantarero Bandrés, Trotta, tercera edición, Madrid, 1998.

${ }^{33}$ Ver Alchourrón, C., "Sobre Derecho y lógica", traducido por Jorge L. Rodríguez con la colaboración de Sergio A. Militello, en Isonomía: Revista de Teoría y Filosofía del Derecho, octubre 2000, No 13, p. 11.

${ }^{34}$ Ver De Asís Roig, R., Jueces y normas. La decisión judicial desde el ordenamiento, Marcial Pons, Madrid, 1995, p. 223.

35 De Asís Roig, R., Jueces y normas. La decisión judicial desde el ordenamiento, Marcial Pons, Madrid, 1995, p. 161.

${ }^{36}$ Ver Alexy, R., Teoría de la argumentación jurídica, traducción de Manuel Atienza e Isabel Espejo, Centro de Estudios Constitucionales, Madrid, primera reimpresión, 1999, pp. 23 y 24.

37 Posner, R., Cómo deciden los jueces, traducción de Victoria Roca Pérez, Marcial Pons, Madrid, 2011, p. 12. 
Gamonal, S., y Guidi, C., Manual del contrato de trabajo, AbeledoPerrot (LegalPublishing), Santiago de Chile, 2012.

Halim, F., El recurso de unificación de jurisprudencia laboral Puntolex y Thomson Reuters), Santiago de Chile, tomo I, 2011.

LANATA, G., El sistema de recursos en el proceso laboral chileno, AbeledoPerrot y Thomson Reuters, Santiago de Chile, segunda edición, 2011.

Lanata, G., Contrato individual de trabajo, AbeledoPerrot (LegalPublishing), Santiago de Chile, 2010.

Melis, C., y Sáez, F., El contrato individual de trabajo en los dictámenes de la Dirección del Trabajo, LegalPublishing, Santiago de Chile, tercera edición, 2011.

Peces-Barba Martínez, G. (con la colaboración de Rafael De Asís Roig, Carlos R. Fernández Liesa y Ángel Llamas Cascón), Curso de derechos fundamentales, Universidad Carlos III de Madrid y Boletín Oficial del Estado, Madrid, primera reimpresión, 1999.

Posner, R., Cómo deciden los jueces, traducción de Victoria Roca Pérez, Marcial Pons, Madrid, 2011.

Thayer, W., y Novoa, P., Manual de Derecho del trabajo, Jurídica de Chile, Santiago de Chile, tomo IV, reimpresión de la quinta edición, 2014.

\section{Artículos de publicaciones periódicas}

Arellano Ortiz, P., y Ponce Heinsohn, I., "Interpretación jurisprudencial del beneficio de la semana corrida: violación del principio de igualdad de remuneraciones", en Revista de Derecho (Valdivia) (vol. XXIV, No 2, diciembre 2011, pp. 27-234.

Delgado Castro, J., "Examen crítico del recurso de unificación de jurisprudencia”, en: Revista de Derecho de la Pontificia Universidad Católica de Valparaíso (№ 36, junio de 2011), pp. 473-494.

Díaz García, L. I., "Objetivo del recurso de unificación de jurisprudencia laboral", en Revista Ius et Praxis, aceptado para publicación.

Halpern, C., y Humeres, H., "La intervención de la Corte Suprema en la nueva justicia del trabajo: el recurso de unificación de jurisprudencia”, en: Actualidad Jurídica Universidad del Desarrollo, año XI, No 21,2010 , pp. 345-374.

Restrepo Medina, M. A. "La adecuación del Derecho administrativo al Estado contemporáneo", en Estudios Socio-Jurídicos, Bogotá, vol. 4, № 2, 2002, pp. 130-153.

Romero Seguel, A., "La discriminación judicial como nuevo error decisorio litis en el proceso chileno”, en Revista Chilena de Derecho (vol. 38, 2011, N²), pp. 339-348.

\section{Documentos en formato electrónico}

Alchourrón, C., "Sobre Derecho y lógica", traducido por Jorge L. Rodríguez con la colaboración de Sergio A. Militello, en Isonomía: Revista de Teoría y Filosofía del Derecho, octubre 2000, $\mathrm{N}^{\circ} 13$. Disponible en la Word Wide Web: http://www.cervantesvirtual. com/servlet/SirveObras/01474064433736395354480/index.htm. [Fecha de visita: 2 de agosto de 2007].

Biblioteca del Congreso Nacional (2008): Historia de la ley 20.260. Disponible en: http://www. leychile.cl/Consulta/portada_hl?tipo_norma $=$ XX1\&nro_ley $=20260 \&$ anio $=2013$. [ Fecha de visita: 25 de agosto de 2013].

4. Leyes

Decreto con fuerza de ley $\mathrm{N}^{\circ} 1 / 19.653$, de 13 de diciembre de 2000, que fija texto refundido, coordinado y sistematizado de la ley 18.575, Orgánica Constitucional de Bases Generales de la 
Administración del Estado. Disponible en: http://www.leychile.cl/Navegar?idNorma=191865. [Fecha de visita: 10 de julio de 2014].

CóDigo de Procedimiento Civil. Disponible en: http://www.leychile.cl/Navegar?idNorma=22 740\&idParte $=0$. [Fecha de visita: 30 de julio de 2014].

Decreto con fuerza de ley 1 , de 31 de julio de 2002, que fija el texto refundido, coordinado y sistematizado del Código del Trabajo. Disponible en: http://www.leychile.cl/Navegar?idN orma $=207436 \&$ idParte $=0$. [Fecha de visita: 30 de junio de 2014 $]$.

Decreto con fuerza de ley $\mathrm{N}^{\circ} 1$, de 9 de mayo de 2006, que fija texto refundido, coordinado y sistematizado de la Ley 18.695, Orgánica Constitucional de Municipalidades. Disponible en: http://www.leychile.cl/Consulta/listaresultadosimple? cadena $=18.695$ \&exacta $=1 .[$ Fecha de visita: 10 de julio de 2014].

Dirección de Estudio, Análisis y Evaluación de la Corte Suprema, Informe No 33-2014, "Doctrina establecida por la Corte Suprema en materia laboral a través de los recursos de unificación de jurisprudencia acogidos entre enero 2011 a junio 2014", junio 2014. Disponible en: http://pjudbeta.pjud.cl/documents/396729/0/UNIFICACION + MATERIA+LABORAL. pdf/a8ac22bd-f3d2-4b31-b4d3-256986f53053. [Fecha de visita: 17 de julio de 2014].

\section{Sentencias}

Gilberto Santana Díaz con Víctor Fugielle y Cía. Ltda. (2008): Corte Suprema, 28 de octubre de 2008 (rrso de unificación de jurisprudencia, rol 5164-2008).

Juan Carlos Ramírez Cortés con Pietro Depetris e Hijos y Cía. Ltda. (2009): Corte Suprema, 11 de marzo de 2009 (recurso de unificación de jurisprudencia, rol 7355-2008).

JAIme Ledesma Herrera y otros con Velásquez S.A. y Anglo América S.A. (2009): Corte Suprema, 2 de abril de 2009 (recurso de unificación de jurisprudencia, rol 1651-2009).

Ocaranza Godoy Waldo con Velásquez S.A. y Anglo América S.A. (2009): Corte Suprema, 18 de junio de 2009 (recurso de unificación de jurisprudencia, rol 3158-2009).

Águila con Servicios Forestales S.A. (2010): Corte Suprema, 31 de marzo de 2010 (recurso de unificación de jurisprudencia, rol 9301-2009).

Mejías con Municipalidad de Valdivia (2010): Corte Suprema, 31 de marzo de 2010 (recurso de unificación de jurisprudencia rol 8809-2009).

NúÑEZ con Sociedad Contractual Minera Tambillos (2010): Corte Suprema, 20 de abril de 2010 (recurso de unificación de jurisprudencia rol 852-2010).

Peralta con Municipalidad de Chiguayante (2010): Corte Suprema, 21 de abril de 2010 (recurso de unificación de jurisprudencia rol 9024-2009).

Vega con Análisis y Servicios S.A. (2010): Corte Suprema, 21 de abril de 2010 (recurso de unificación de jurisprudencia rol 9603-2009).

NúÑEz Sonia y Otros con Ilustre Municipalidad de Lanco (2010): Corte Suprema, 22 de abril de 2010 (recurso de unificación de jurisprudencia rol 627-2010).

Alarcón con Municipalidad de San Pedro de la Paz (2010): Corte Suprema, 28 de abril de 2010 (recurso de unificación de jurisprudencia rol 212-2010).

Ayala con Corporación Municipal de Desarrollo Social de Iquique (2010): Corte Suprema, 28 de abril de 2010 (recurso de unificación de jurisprudencia rol 7930-2009).

CeA y Otros con I. Municipalidad de Coronel (2010): Corte Suprema, 9 de junio de 2010 (recurso de unificación de jurisprudencia rol 1167-2010).

Machuca con Ilustre Municipalidad de San Pedro de la Paz (2010): Corte Suprema, 9 de junio de 2010 (recurso de unificación de jurisprudencia rol 171-2010).

Ramírez con Ilustre Municipalidad de Hualpén (2010): Corte Suprema, 9 de junio de 2010 (recurso de unificación de jurisprudencia rol 915-2010). 
Candia con I. Municipalidad de Yumbel (2010): Corte Suprema, 15 de junio de 2010 (recurso de unificación de jurisprudencia rol 1346-2010).

Castro y Otros con Municipalidad de Colbún (2010): Corte Suprema, 15 de junio de 2010 (recurso de unificación de jurisprudencia rol 1984-2010).

Espinosa con I. Municipalidad de Linares (2010): Corte Suprema, 15 de junio de 2010 (recurso de unificación de jurisprudencia rol 3357-2010).

GonZÁLEZ con Ilustre Municipalidad de los Ángeles (2010): Corte Suprema, 15 de junio de 2010 (recurso de unificación de jurisprudencia rol 2975-2010).

Sepúlveda con Ilustre Municipalidad de Talcahuano (2010): Corte Suprema, 15 de junio de 2010 (recurso de unificación de jurisprudencia rol 1312-2010).

Uribe y Otro con I. Municipalidad de Paillaco (2010): Corte Suprema, 15 de junio de 2010 (recurso de unificación de jurisprudencia rol 1985-2010).

Bustamante y Otro con I. Municipalidad de Parral (2010): Corte Suprema, 16 de junio de 2010 (recurso de unificación de jurisprudencia rol 1584-2010).

PÉrez y Otros con I. Municipalidad de Mariquina (2010): Corte Suprema, 24 de junio de 2010 (recurso de unificación de jurisprudencia rol 2419-2010).

Avendaño y Otros con Ilustre Municipalidad de Curepto (2010): Corte Suprema, 29 de junio de 2010 (recurso de unificación de jurisprudencia rol 1349-2010).

Ávila y Otros con Ilustre Municipalidad de Parral (2010): Corte Suprema, 29 de junio de 2010 (recurso de unificación de jurisprudencia rol 1954-2010).

EnCina y Otros contra I. Municipalidad de Yerbas (2010): Corte Suprema, 29 de junio de 2010 (recurso de unificación de jurisprudencia rol 1586-2010).

Alejandrina con Ilustre Municipalidad de Talca (2010): Corte Suprema, 30 de junio de 2010 (recurso de unificación de jurisprudencia rol 1392-2010).

Corvalán con Ilustre Municipalidad de Talca (2010): Corte Suprema, 30 de junio de 2010 (recurso de unificación de jurisprudencia rol 1345-2010).

LiBis con Municipalidad de Valdivia (2010): Corte Suprema, 30 de junio de 2010 (recurso de unificación de jurisprudencia rol 1639-2010).

Lienlaf Marilaf y Otras con I. Municipalidad de Mariquina (2010): Corte Suprema, 30 de junio de 2010 (recurso de unificación de jurisprudencia rol 629-2010).

Medel con Ilustre Municipalidad de Talca (2010): Corte Suprema, 30 de junio de 2010 (recurso de unificación de jurisprudencia rol 1489-2010).

Rivera con Ilustre Municipalidad de Talca (2010): Corte Suprema, 30 de junio de 2010 (recurso de unificación de jurisprudencia rol 1491-2010).

SAN Martín con Ilustre Municipalidad de Talcahuano (2010): Corte Suprema, 30 de junio de 2010 (recurso de unificación de jurisprudencia rol 2454-2010).

Agurto y Otros con Ilustre Municipalidad de Cauquenes (2010): Corte Suprema, 13 de julio de 2010 (recurso de unificación de jurisprudencia rol 3352-2010).

INOCENCIO con I. Municipalidad de Quillota (2010): Corte Suprema, 13 de julio de 2010 (recurso de unificación de jurisprudencia rol 3609-2010).

Arancibia y Otros con Ilustre Municipalidad de Quillota (2010): Corte Suprema, 28 de julio de 2010 (recurso de unificación de jurisprudencia rol 3488-2010).

Moya con Ilustre Municipalidad de Linares (2010): Corte Suprema, 28 de julio de 2010 (recurso de unificación de jurisprudencia rol 3718-2010).

Muena y Otros con Municipalidad de Linares (2010): Corte Suprema, 28 de julio de 2010 (recurso de unificación de jurisprudencia rol 1959-2010).

Concha con Ilustre Municipalidad de Constitución (2010): Corte Suprema, 4 de agosto de 2010 (recurso de unificación de jurisprudencia rol 2578-2010). 
Silva con Municipalidad de Huechuraba (2010): Corte Suprema, 2 de septiembre de 2010 (recurso de unificación de jurisprudencia rol 3991-2010).

Herrera con Corporación de Desarrollo Social (2010): Corte Suprema, 9 de septiembre de 2010 (recurso de unificación de jurisprudencia rol 3846-2010).

Aguilera con I. Municipalidad de Curicó (2010): Corte Suprema, 14 de septiembre de 2010 (recurso de unificación de jurisprudencia rol 3358-2010).

Corvera con Ilustre Municipalidad de El Bosque (2010): Corte Suprema, 16 de septiembre de 2010 (recurso de unificación de jurisprudencia rol 3292-2010).

Corvera con Ilustre Municipalidad de El Bosque (2010): Corte Suprema, 16 de septiembre de 2010 (recurso de unificación de jurisprudencia rol 3293-2010).

NeIra con I. Municipalidad de Hualqui (2010): Corte Suprema, 16 de septiembre de 2010 (recurso de unificación de jurisprudencia rol 3013-2010).

LorCa y Otros con Ilustre Municipalidad de Arauco (2010): Corte Suprema, 30 de septiembre de 2010 (recurso de unificación de jurisprudencia rol 5062-2010).

Villanueva con Fisco de Chile Armada de Chile (2010): Corte Suprema, 26 de octubre de 2010 (recurso de unificación de jurisprudencia rol 5447-2010).

Alegría con Laboratorio Koni Cofarm S.A. (2010): Corte Suprema, 28 de octubre de 2010 (recurso de unificación de jurisprudencia rol 4196-2010).

Constant y Otros con Ilustre Municipalidad de Lebu (2010): Corte Suprema, 3 de noviembre de 2010 (recurso de unificación de jurisprudencia rol 5010-2010).

Araneda y Otros con Ilustre Municipalidad de los Álamos (2010): Corte Suprema, 9 de noviembre de 2010 (recurso de unificación de jurisprudencia rol 5833-2010).

Fuentez y Otros con Ilustre Municipalidad de Lebu (2010): Corte Suprema, 11 de noviembre de 2010 (recurso de unificación de jurisprudencia rol 5011-2010).

Bravo con Corporación de Desarrollo I. Municipalidad de la Reina (2010): Corte Suprema, 15 de noviembre de 2010 (recurso de unificación de jurisprudencia rol 4911-2010).

SiLva con Corporación de Desarrollo Social de Providencia (2010): Corte Suprema, 26 de noviembre de 2010 (recurso de unificación de jurisprudencia rol 5835-2010).

Alarcón con Análisis y Servicios S.A. (2010): Corte Suprema, 30 de noviembre de 2010 (recurso de unificación de jurisprudencia rol 6074-2010).

Meza y Otros con Municipalidad de Hualañé (2010): Corte Suprema, 9 de diciembre de 2010 (recurso de unificación de jurisprudencia rol 6763-2010).

Cárcamo con Ilustre Municipalidad de Puerto Montt (2010): Corte Suprema, 10 de diciembre de 2010 (recurso de unificación de jurisprudencia rol 5132-2010).

Flores y otro con Servicios Prosegur Limitada (2011): Corte Suprema, 6 de enero de 2011 (recurso de unificación de jurisprudencia rol 5881-2010).

Corvera con Instituto de Previsión Social (2011): Corte Suprema, 25 de enero de 2011 (recurso de unificación de jurisprudencia, rol 6246-2010).

ZúÑ̃IgA con Transportes Aéreos del Mercosur S.A. (2011): Corte Suprema, 26 de enero de 2011 (recurso de unificación de jurisprudencia rol 7362-2010).

A.F.P. Provida con Román (2011): Corte Suprema, 27 de enero de 2011 (recurso de unificación de jurisprudencia rol 4751-2010).

Gómez con ING AFP Capital S.A. (2011): Corte Suprema, 27 de enero de 2011 (recurso de unificación de jurisprudencia rol 6019-2010).

Prado con ING AFP Capital S.A. (2011): Corte Suprema, 27 de enero de 2011 (recurso de unificación de jurisprudencia rol 6552-2010).

Canales y otros con I. Municipalidad de San Rosendo (2011): Corte Suprema, 23 de marzo de 2011 (recurso de unificación de jurisprudencia rol 4371-2010). 
ReYes con A.F.P. Próvida S.A. (2011): Corte Suprema, 25 de marzo de 2011 (recurso de unificación de jurisprudencia rol 6101-2010).

Cabrera con A.F.P. Próvida S.A. (2011): Corte Suprema, 28 de marzo de 2011 (recurso de unificación de jurisprudencia rol 6114-2010).

Pereira con A.F.P. Próvida S.A. (2011): Corte Suprema, 28 de marzo de 2011 (recurso de unificación de jurisprudencia rol 6115-2010).

Ahumada [esta es la carátula de la página web del Poder Judicial] (2011): Corte Suprema, 29 de marzo de 2011 (recurso de unificación de jurisprudencia rol 7828-2010).

CÁceres con ING AFP Capital S.A. (2011):Corte Suprema, 29 de marzo de 2011 (recurso de unificación de jurisprudencia rol 6777-2010).

Mora con Municipalidad de Chiguayante (2011): Corte Suprema, 29 de marzo de 2011 (recurso de unificación de jurisprudencia rol 6973-2010).

Monroy y otra con AFP Hábitat S.A. (2011): Corte Suprema, 31 de marzo de 2011 (recurso de unificación de jurisprudencia rol 6450-2010).

FERnÁndeZ con Inesa Chile S.A. (2011): Corte Suprema, 12 de abril de 2011 (recurso de unificación de jurisprudencia rol 8155-2010).

Córdova con Ilustre Municipalidad de Curicó (2011): Corte Suprema, 13 de mayo de 2011 (recurso de unificación de jurisprudencia rol 8859-2010).

Rencoret y Otro con AFP Provida S.A. (2011): Corte Suprema, 13 de mayo de 2011 (recurso de unificación de jurisprudencia rol 7208-2010).

SALGado con Toledo y otros (2011): Corte Suprema, 31 de mayo de 2011 (recurso de unificación de jurisprudencia, rol 8316-2010).

Caro y Otros con AFP Provida S.A. (2011): Corte Suprema, 3 de junio de 2011 (recurso de unificación de jurisprudencia rol 6932-2010).

Araya con Bodega La Esperanza Viñedos Errázuriz Ovalle S.A. (2011): Corte Suprema, 16 de junio de 2011 (recurso de unificación de jurisprudencia rol 10120-2010).

Soza con Televisión Nacional de Chile (2011): Corte Suprema, 16 de junio de 2011 (recurso de unificación de jurisprudencia rol 205-2011).

Sindicato de Trabajadores de la AFP Provida S.A. con AFP Provida S.A. (2011): Corte Suprema, 29 de junio de 2011 (recurso de unificación de jurisprudencia rol 1117-2011).

Acosta y Otros con Sociedad Depetris Deflorian Hnos. Ltda. (2011): Corte Suprema, 30 de junio de 2011 (recurso de unificación de jurisprudencia rol 116-2011).

Valenzuela con AFP Capital S.A. (2011): Corte Suprema, 8 de julio de 2011 (recurso de unificación de jurisprudencia rol 8860-2010).

Araya con Monte Nevado Ingeniería y Otros (2011): Corte Suprema, 10 de agosto de 2011 (recurso de unificación de jurisprudencia rol 9375-2010).

CÁrdenas con Corporación Municipal de La Florida (2011): Corte Suprema, 29 de agosto de 2012 (recurso de unificación de jurisprudencia rol 10066-2011).

Osses y Otros con AFP Habitat S.A. (2011): Corte Suprema, 29 de agosto de 2011 (recurso de unificación de jurisprudencia rol 470-2011).

Tudela con Corporación Municipal de Servicio y Desarrollo de Maipú (2011): Corte Suprema, 27 de octubre de 2011 (recurso de unificación de jurisprudencia rol 70-2011).

Monsalve con Sociedad Educacional ArabPerez Ltda (2011): Corte Suprema, 15 de noviembre de 2011 (recurso de unificación de jurisprudencia rol 3169-2011).

CABELlo con Cáceres (2011): Corte suprema, 17 de noviembre de 2011 (recurso de unificación de jurisprudencia rol 3488-2011).

Berríos con Pullman cargo (2011): Corte Suprema, 6 de diciembre de 2011 (recurso de unificación de jurisprudencia rol 3168-2011). 
Alarcón con Administradora de Fondos de Pensiones Capital S.A. (2011): Corte Suprema, 16 de diciembre de 2011 (recurso de unificación de jurisprudencia rol 1863-2011).

Sindicato Unificado de Trabajadores de Isapre Banmédica S.A. con Isapre Banmédica S.A. (2011): Corte Suprema, 16 de diciembre de 2011 (recurso de unificación de jurisprudencia rol 2739-2011).

RodrígueZ con Inversiones Alsacia S.A. (2012): Corte Suprema, 27 de enero de 2012 (recurso de unificación de jurisprudencia rol 4735-2011).

Gallardo con Red Capacita S.A. (2012): Corte Suprema, 24 de abril de 2012 (recurso de unificación de jurisprudencia rol 5843-2011).

RodrígueZ con Instituto de Previsión Social (2012): Corte Suprema, 16 de mayo de 2012 (recurso de unificación de jurisprudencia, rol 4790-2011).

Aravena y Otros con VTR Global Com S.A. (2012): Corte Suprema, 17 de mayo de 2012 (recurso de unificación de jurisprudencia rol 8788-2011).

GonZÁles y Otros con AFP Provida S.A. (2012): Corte Suprema, 6 de junio de 2012 (recurso de unificación de jurisprudencia rol 8322-2011).

Campusano con AFP Planvital S.A. (2012): Corte Suprema, 8 de junio de 2012 (recurso de unificación de jurisprudencia rol 8504-2011).

Caro con Envases Del Pacífico S.A. (2012): Corte Suprema, 14 de junio de 2012 (recurso de unificación de jurisprudencia rol 9242-2011).

Peralta con Corporación Municipal De Edu. Salud y Atenc. De Menores De Puente Alto (2012): Corte Suprema, 3 de agosto de 2012 (recurso de unificación de jurisprudencia rol 10266-2011).

PARADA con AFP Capital S.A. (2012): Corte Suprema, 8 de agosto de 2012 (recurso de unificación de jurisprudencia rol 10713-2011).

Kerbernhard con Recaudación y Cobranzas S.A. (2012): Corte Suprema, 9 de agosto de 2012 (recurso de unificación de jurisprudencia rol 9579-2011).

Azocar con Sociedad Comercial Wingel Ltda. (2012): Corte Suprema, 10 de agosto de 2012 (recurso de unificación de jurisprudencia rol 9838-2011).

Becker con Premium Nutregg S.A. (2012): Corte Suprema, 21 de agosto de 2012 (recurso de unificación de jurisprudencia rol 361-2012).

Loyola con Compass Catering S.A. (2012): Corte Suprema, 21 de agosto de 2012 (recurso de unificación de jurisprudencia rol 208-2012).

Irazzoky con Comercial Rey S.A. (2012): Corte Suprema, 24 de agosto de 2012 (recurso de unificación de jurisprudencia rol 11873-2011).

Ponce con Distribuidora de Industrias Nacionales S.A. DIN (2012): Corte Suprema, 24 de agosto de 2012 (recurso de unificación de jurisprudencia rol 11655-2011).

Orrego con Empresa Periodística La Cuarta S.A. (2012): Corte Suprema, 29 de agosto de 2012 (recurso de unificación de jurisprudencia rol 8989-2011).

Parra y Otros con Ilustre Municipalidad de Temuco (2012): Corte Suprema, 6 de septiembre de 2012 (recurso de unificación de jurisprudencia rol 7871-2011).

Olivares con Pontificia Universidad Católica de Chile (2012): Corte Suprema, 28 de noviembre de 2012 (recurso de unificación de jurisprudencia rol 1855-2012).

Riquelme con Pontificia Universidad Católica de Chile Corporación de Televisión (2012): Corte Suprema, 28 de noviembre de 2012 (recurso de unificación de jurisprudencia rol 1681-2012).

${ }^{1}$ Los porcentajes expresados en el presente trabajo consideran solo decimales. Estos decimales resultan de aproximar las centésimas, elevándolas a la décima superior si son iguales o mayores a 5 y rebajándolas a la décima inferior si son menores a dicha cifra. De este modo, y a modo de ejemplo, la cifra 10,55 se expresa 10,6 y la cifra 10,54 se expresa mediante la décima 10,5 . 